\title{
THIRD INTERNATIONAL CONGRESS ON FUNGAL CONSERVATION
}

\section{Gökova Bay, Muğla, Turkey, 11-15 \\ November 2013}

For nature conservation to be successful, it is critically important to ensure that fungi get just as much protection as animals and plants. There is no sense in protecting the producers and consumers without also conserving the recyclers. Interest in fungal conservation is growing very rapidly. Following its establishment in July 2010, the International Society for Fungal Conservation (IFSC) has grown six-fold and this year organized the third international congress devoted to this work. The previous congress, in England in 2009, laid the way for establishing this society, and the first congress, in Spain in 2007 brought fungal conservation to the global arena. Since its formation, the IFSC has successfully lobbied for change in the wording of the Global Strategy for Plant Conservation to make clear that fungi are not plants but also need separate protection. It was also involved in preparation of a motion recognizing the importance of fungi in nature conservation which was adopted by and is now policy of the International Union for Conservation of Nature (IUCN).

The Congress in Turkey was vibrant and exciting. Participants from a very wide range of countries (including Australia, Chile, Colombia, Egypt, France, Ghana, Guatemala, India, Italy, Latvia, Lithuania, Malaysia, New Zealand, Russia, Serbia, Spain, Sweden, Switzerland, Turkey, Ukraine, the UK, the USA, and Zimbabwe) looked at threats faced by fungi, and ways to address those threats, including an examination of the political processes involved, with a keynote address from the Chair of the Species Survival Commission of the IUCN, and another key presentation from one of Australia's most distinguished but now retired politicians. Speaker after speaker emphasized the importance for conservation of making clear that fungi are distinct from plants, and that conservation of animals and plants does not necessarily also result in conservation of fungi.

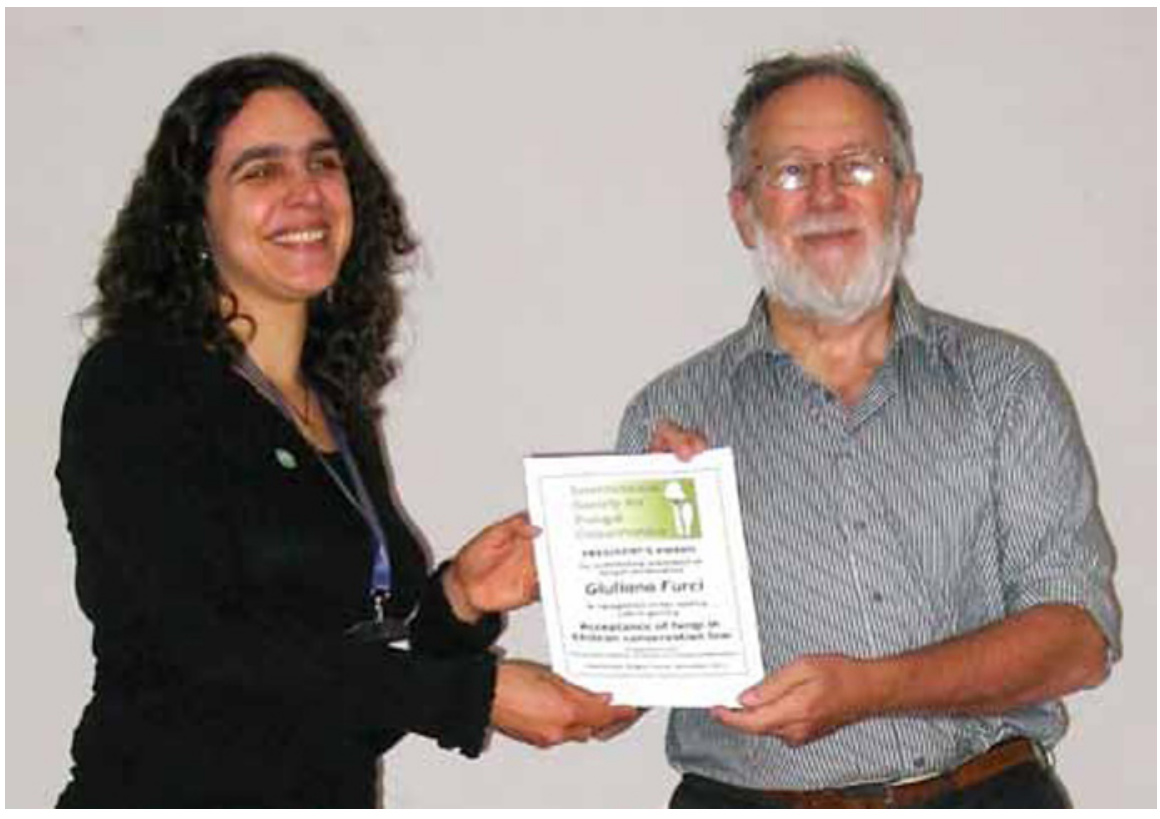

Giuliana Furci being presented with the President's Award by ISFC president, David Minter. Photo: Boris Ivancevic.

The Congress honoured three people for their outstanding contributions to fungal conservation. The Founders' Award was given to Maria Ławrynowicz of Poland for lifetime achievement through her rôle in establishing the European Council for Conservation of Fungi and for her work to protect hypogeous fungi. Ahmed AbdelAzeem of Egypt, and Giuliana Furci of Chile were each given the President's Award for their pioneering work. Ahmed established the Arab Society for Fungal Conservation, and Guiliana set up Fundación Fungi, an NGO which has already succeeded in getting Chilean conservation legislation changed specifically to include fungi.

Thanks to generous support from the Mohamed Bin Zayed Species Conservation Fund, a series of workshops were held during the Congress. The most important, ably led by Greg Mueller and Michael Krikorev, was devoted to the red-listing process for fungi using IUCN categories and criteria and a new website specifically developed to promote fungal red-listing (http:// iucn.ekoo.se/en/iucn/welcome). This was accompanied by sister workshops on desert truffle conservation, information sources for fungal conservation, and conservation of myxomycetes.

Although fungal conservation is a political activity, it is driven by science. This important point is recognized in the Constitution of the IFSC which gives a seat on its council to the International Mycological Association to ensure close liaison. Membership of the ISFC is currently free of charge. The Society wants to build up a cadre of people interested in supporting this important topic. All mycologists are warmly invited to join. ISFC Membership application forms can be downloaded from the Society's website: www.fungalconservation.org.

David W. Minter
President, International Society for Fungal
Conservation
(d.minter@cabi.org)

